\title{
Formation of Bilirubin Conjugates in Human Newborns
}

\author{
PHILIP ROSENTHAL, NORBERT BLANCKAERT, POKAR M. KABRA, AND \\ M. MICHAEL THALER \\ Departments of Pediatrics and Laboratory Medicine, University of California, San Francisco Medical Center, \\ San Francisco, California 94143
}

\begin{abstract}
Bilirubin conjugates in the serum of newborn human infants were investigated using the alkaline methanolysis-high-performance liquid chromatography method, a specific and sensitive method for measurement of unconjugated bilirubin and bilirubin mono- and diester conjugates. Serum samples were analyzed from 13 premature infants, 11 full term newborns, 22 healthy adults, seven pregnant women at term and their corresponding infants cord blood at delivery, 46 cord blood specimens obtained at unselected deliveries, three cord bloods from infants with maternal-fetal blood group incompatibility, and two cord bloods from infants with intrauterine hypoxia. Bilirubin conjugates were not detectable in the healthy adults, maternal blood, or in the cord blood specimens except from infants with blood group incompatibility or intrauterine hypoxia. The two isomeric monoconjugates of bilirubin appeared in serum during the first 24 to 48 postnatal $h$ in both premature and full term infants, followed by the diconjugate on the 3rd day. Conjugated esters accounted for 2 to $5 \%$ of the total bilirubin, with the diconjugate constituting $21 \%$ of total conjugated pigment (day 3 ). In all instances, the unconjugated serum bilirubin concentration had increased to at least $2 \mathrm{mg} / \mathrm{dl}$ in the course of physiologic neonatal hyperbilirubinemia before bilirubin conjugates became detectable. Both premature and full term human infants displayed the identical pattern of bilirubin conjugation in serum. (Pediatr Res 20:947-950, 1986)
\end{abstract}

\section{Abbreviation}

AM-HPLC, alkaline methanolysis-high-performance liquid chromatography

Physiologic jaundice refers to the transient hyperbilirubinemia which normally develops during the first 3 to 5 days after birth in the human newborn infant $(1,2)$. This process is presumed to reflect maturational deficiency of bilirubin glucuronyl transferase (UDP glucuronate $\beta$-glucuronosyl transferase EC 2.4.1.17), the enzyme system responsible for bilirubin conjugation (3). Studies in animals have demonstrated that bilirubin glucuronyl transferase activity is undetectable in fetal liver, but increases after birth at rates which exhibit considerable species variability (4-7). In

Received March 12, 1986; accepted May 15, 1986.

Correspondence and reprint requests to Philip Rosenthal, M.D., Division of Gastroenterology, Childrens Hospital of Los Angeles, 4650 Sunset Boulevard, Los Angeles, CA 90027

This work was supported in part by Grants AM-07179, AM-11275, and HD03148 from the NIH, USPHS. utero, fetal bilirubin is cleared by the placenta. At birth the neonatal liver must assume detoxification and elimination of bilirubin. The mechanisms responsible for development of bilirubin conjugation after birth are poorly understood. Evidence for substrate-dependent stimulation of bilirubin conjugation in heterozygous newborn Gunn rats has been reported by Thaler (8) but studies of bilirubin conjugation in human neonates have not been performed due to unavailability of adequate methods. The gestation age at which the capacity for bilirubin conjugation is acquired and the types of conjugates initially formed are unknown. A highly specific and sensitive method for the measurement of unconjugated bilirubin and bilirubin mono- and diester conjugates in biologic fluids has been developed in our laboratory $(9,10)$. By utilizing this procedure, we investigated the appearance of bilirubin conjugates in serum of human neonates during the period of physiologic jaundice.

\section{MATERIALS AND METHODS}

Collection of serum specimens. Forty-three serial serum samples obtained in the course of routine laboratory evaluation from 13 premature infants (six male, seven female) of 25-36 wk gestational age were compared with 25 samples from 11 fullterm newborns (six male, five female) of 37-41 wk gestational age during the first 3 days of life. Birth weights for the premature infant group ranged from 590-3000 g while full-term infant's birth weights ranged between $2500-3900 \mathrm{~g}$. Infants with evidence of hemolysis or liver disease were excluded from the study.

For comparison, serum samples from 22 healthy adults, seven pregnant women at term and their corresponding infant's cord blood at delivery, 46 cord blood specimens obtained at unselected deliveries, and five cord blood specimens from neonates with intrauterine hyperbilirubinemia due to blood group incompatibility or hypoxia also were examined.

All specimens were protected from light in containers wrapped in aluminum foil, and were assayed immediately or after storage in the light-shielded containers at $-12^{\circ} \mathrm{C}$ for less than $1 \mathrm{wk}$.

Analytical methods. All procedures were performed in dim light. The AM-HPLC method for analysis of serum bilirubins has been previously described $(9,10)$. About $60 \mathrm{mg}$ of sodium ascorbate, 2-3 mg of disodium ethylene diamine tetraacetate, 4 $\mathrm{ml}$ of methanol, and $2 \mathrm{ml}$ of methanol containing the internal standard xanthobilirubic acid methyl ester were mixed with 0.6 $\mathrm{ml}$ of serum. The mixture was treated with $6 \mathrm{ml}$ of $2 \%(\mathrm{w} / \mathrm{v})$ $\mathrm{KOH}$ in methanol and immediately vortex-mixed. After reaction for $60-90 \mathrm{~s}$ at $20-25^{\circ} \mathrm{C}, 6 \mathrm{ml}$ of chloroform and $12 \mathrm{ml}$ of glycine/ $\mathrm{HCl}$ buffer $(0.4 \mathrm{M} \mathrm{HCl}$ brought to $\mathrm{pH} 2.4$ with solid glycine) were added sequentially. Organic and aqueous phases were separated by brief centrifugation, the organic phase was transferred to a dry tube, and the extract evaporated to dryness under nitrogen at $30^{\circ} \mathrm{C}$. The residue was stored under argon at $-12^{\circ} \mathrm{C}$ and analyzed within $1 \mathrm{wk}$. 
The pigment residue obtained from alkaline methanolysis was redissolved in $100 \mu \mathrm{l}$ of chloroform and $25 \mu \mathrm{l}$ of the solution injected in the liquid chromatograph. Pigment separation, peak assignment, and calculation of results were obtained as previously reported $(9,10)$. The methodology employed measured bilirubin in serum down to $0.01 \mathrm{mg} / 100 \mathrm{ml}$ with an accuracy of $5 \%$ (10).

All reagents were purchased from commercial sources and were analytical-reagent grade. The internal standard, crystalline methyl ester of xanthobilirubic acid was prepared as described by Grunewald et al. (11).

For statistical analysis the Student's $t$ test was used; $p \leq 0.05$ was considered to be significant.

\section{RESULTS}

Mean total serum bilirubin values in healthy adults, pregnant women at term and their corresponding infant's cord blood, and unselected cord bloods from uncomplicated deliveries are presented in Figure 1. Of significance, the total bilirubin consisted entirely of unconjugated pigment by this method. The difference observed between the bilirubin concentration in serum of pregnant women at term and in cord blood serum from each corresponding infant was highly significant $(p<0.001)$. In contrast, cord blood samples from the blood group incompatible and intrauterine hypoxic infants contained unconjugated bilirubin in concentration $>2 \mathrm{mg} / \mathrm{dl}$ and esterified bilirubins were detectable in these samples (Fig. 2).

During the first 3 days of life, serum from premature and fullterm newborn human infants contained measurable amounts of esterified bilirubin as seen in Figures 3 and 4 . Monoesters of bilirubin appeared during the first 24 to $48 \mathrm{~h}$ after birth, and the diester followed on the 3 rd day increasing to $21 \%$ of the total esters. The C-8 monoester was the predominant bilirubin conjugate fraction observed. In premature infants mean total serum bilirubin values were $3.3 \pm 1.8$ (SD) for day $1,4.2 \pm 2.3$ for day 2 , and $3.3 \pm 2.1 \mathrm{mg} / \mathrm{dl}$ for day 3 . In full-term infants mean total serum bilirubin values were $2.9 \pm 2$ for day $1,4.2 \pm 1.9$ for day 2 , and $4.9 \pm 1.4 \mathrm{mg} / \mathrm{dl}$ for day 3 . In all instances, the serum bilirubin concentration reached at least $2 \mathrm{mg} / \mathrm{dl}$ before bilirubin

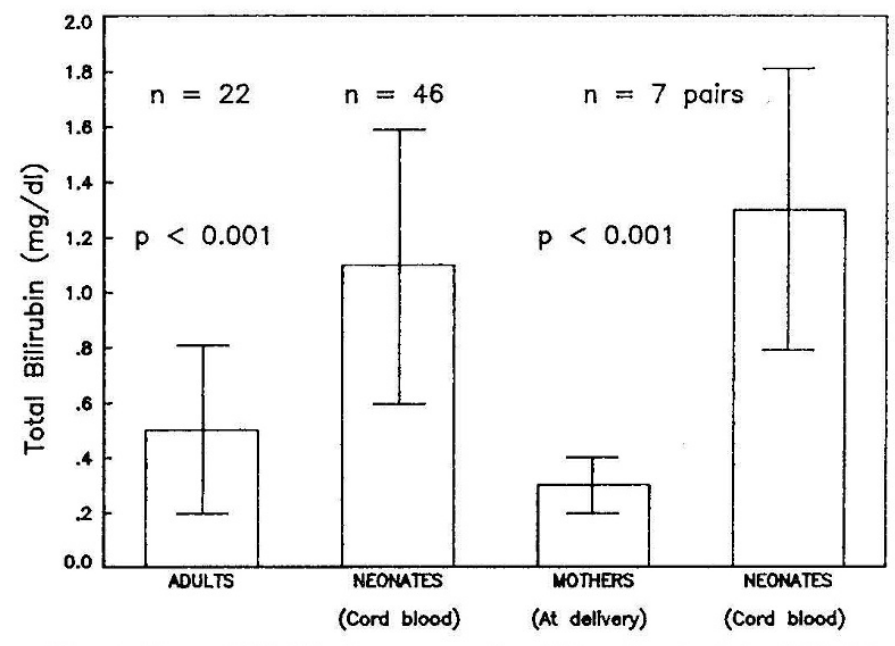

Fig. 1. Serum bilirubin in neonates (cord blood) and adults. Bilirubin was all in unconjugated form. Values are mean $\pm \mathrm{SD}$.

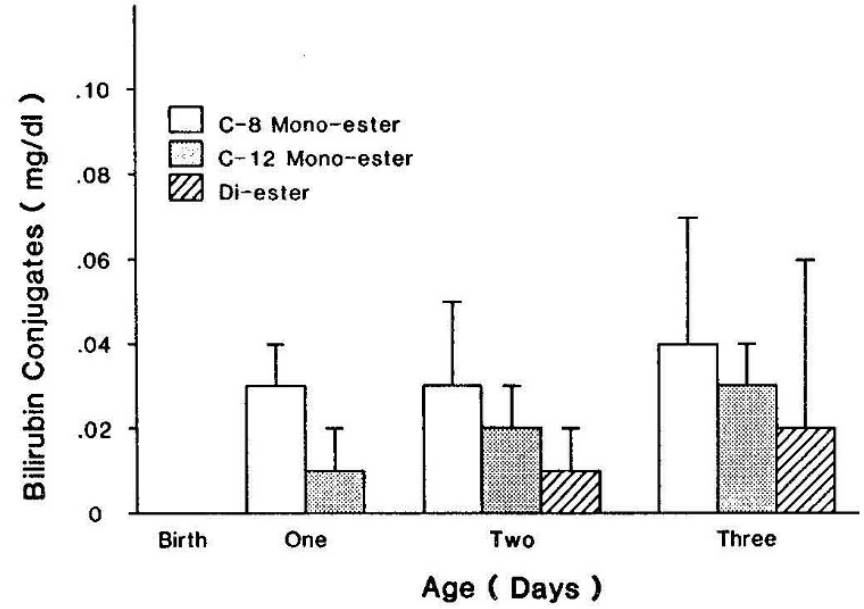

Fig. 3. Bilirubin conjugates in the serum of human premature newborn infants. C-8 monoester was the predominant conjugate in all instances. All concentrations are expressed as the mean value $( \pm \mathrm{SD})$ for each fraction observed daily.

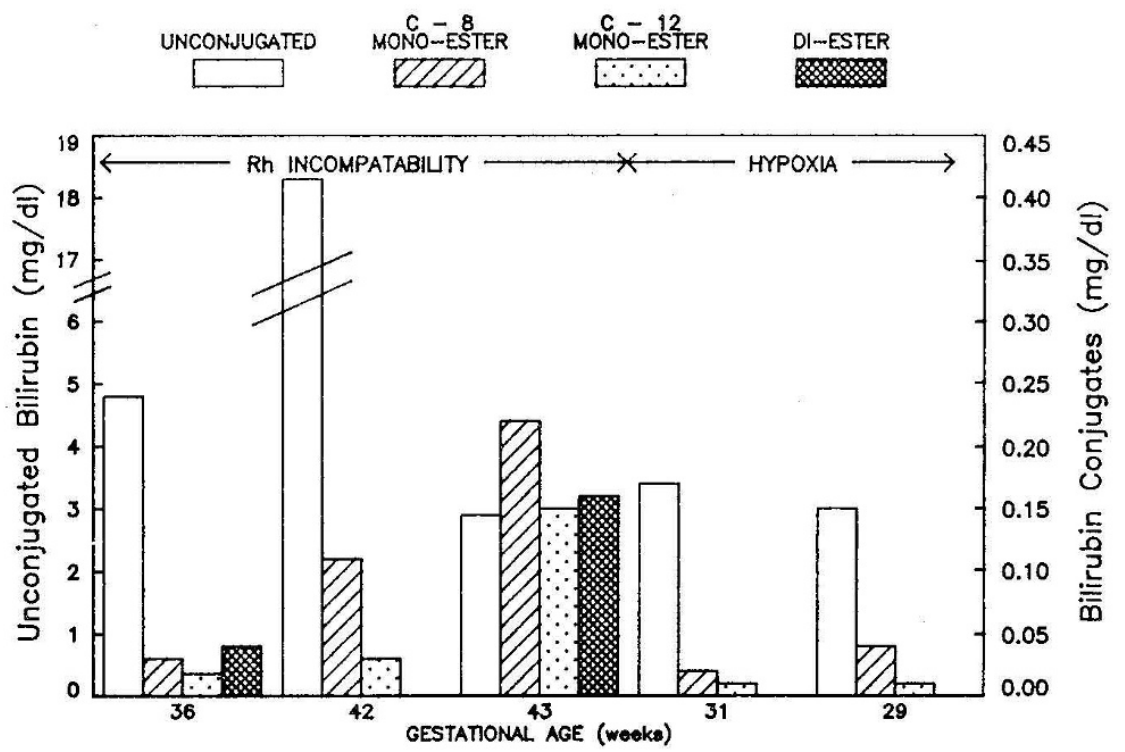

Fig. 2. Serum bilirubin in the cord blood of neonates with intrauterine hyperbilirubinemia. There is a break in the unconjugated bilirubin scale between 6 and $17 \mathrm{mg} / \mathrm{dl}$. Note the presence of mono- and diesters. 


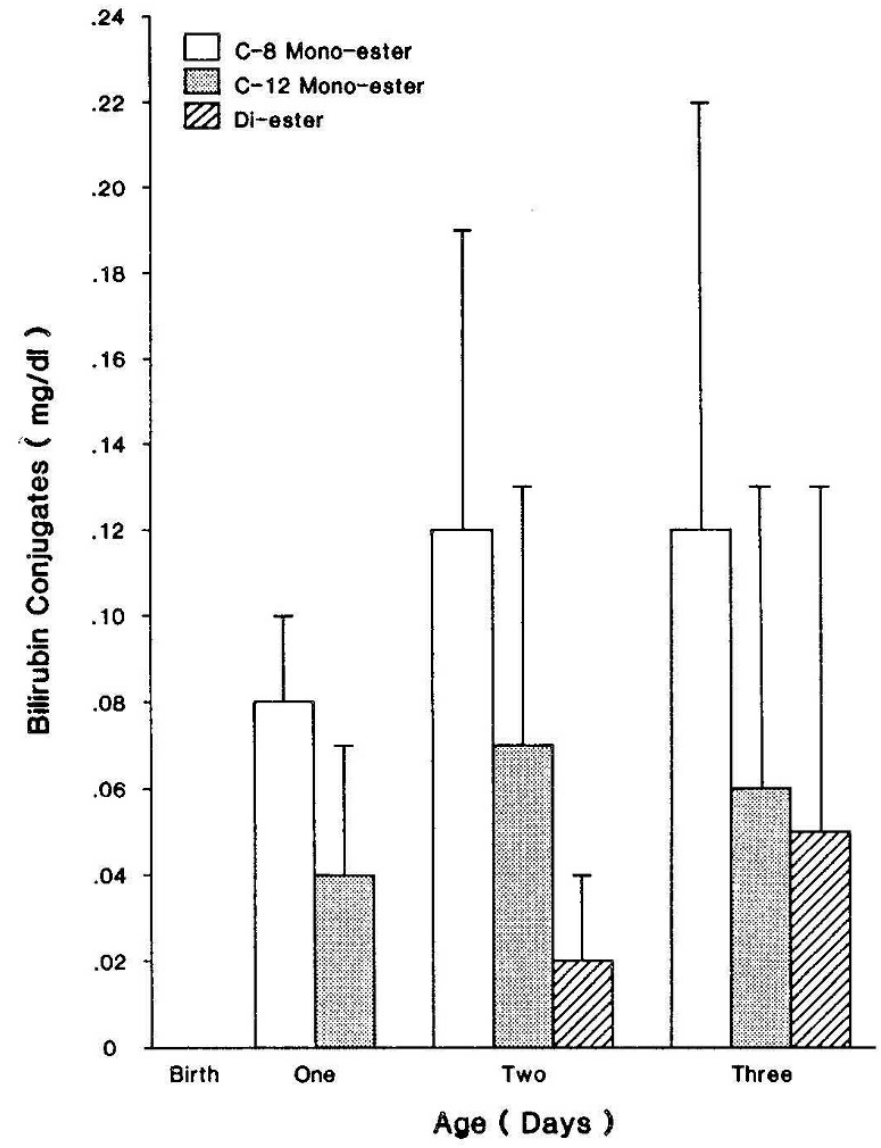

Fig. 4. Bilirubin conjugates in the serum of human full term newborn infants. C-8 monoester was the predominate conjugate.

esters became detectable in the infant's serum. The entire conjugated fraction (monoconjugates plus diconjugate) accounted for 2 to $5 \%$ of the total bilirubin value. The fraction of the total bilirubin represented by conjugates remained constant during the 3 days studied. Bilirubin esters were detected in the serum samples of a premature infant of only $25 \mathrm{wk}$ gestation. In general, bilirubin conjugate levels were higher in the serum of full-term infants than premature infants (Figs. 3 and 4).

\section{DISCUSSION}

Cord blood is normally devoid of conjugated bilirubin. In utero, the placenta clears the unconjugated bilirubin produced by the fetus. Cord blood contains bilirubin in a concentration four times higher than in maternal serum. Thus, the gradient of bilirubin flow is from fetus to mother. In contrast with normal newborns, infants with prenatal hyperbilirubinemia are capable of forming bilirubin conjugates in utero. Concentrations of direct reacting pigment up to $10 \mathrm{mg} / \mathrm{dl}$ have been found in the gallbladders of such fetuses (12). These data indicate that bilirubin UDP-glucuronosyl-transferase activity can be prematurely induced in utero in the presence of chronically elevated concentrations of the pigment substrate.

After birth, with cessation of placental function, the neonatal liver must assume bilirubin conjugating activity. In both premature and full-term infants conjugation begins in a distinct sequence. Monoconjugated bilirubin appears in the serum during the first 24 to $48 \mathrm{~h}$. Diconjugated esters follow thereafter. These findings suggest that bilirubin conjugation is normally initiated in both premature and full-term infants as physiologic jaundice develops during the first days of life. When total serum bilirubin levels rise to levels $>2 \mathrm{mg} / \mathrm{dl}$ after birth, bilirubin conjugates become detectable. In the rat, unconjugated bilirubin stimulates bilirubin UDP-glucuronosyltransferase activity and thereby induces its own conjugation with glucuronide $(8,13)$. The observations in the human newborn infants and in the cord blood samples from infants with prenatal hyperbilirubinemia are consistent with the findings in rats and suggests that bilirubin may participate in inducing its own conjugation during the perinatal period.

Defective transport of bile acids in early life has been suggested by studies demonstrating elevated serum bile acid concentrations, impaired bile acid uptake, and impaired transport and excretion of organic anions by animals and human infants (1416). The present study shows that the ratio of bilirubin conjugates to the total bilirubin value remains constant during the period of physiologic jaundice. With cholestasis, the conjugated fraction of serum bilirubin would be expected to increase. This finding suggests that accumulation of conjugated bilirubins is not a significant component of physiologic jaundice and differs from the bile acid observations. The bilirubin data are consistent with immature enzyme activity rather than impaired transport of conjugated bilirubin.

The detection of monoconjugated forms of bilirubin prior to the detection of diconjugated bilirubin suggests a possible transition from an immature to a mature enzyme system for bilirubin conjugation. Maturation of conjugation appears to favor formation of monoconjugates initially. This may be advantageous to the newborn since the potentially toxic unconjugated bilirubin that is accumulating becomes water soluble when converted to the monoconjugate form and more readily disposable in bile. Further, the process is efficient since only one sugar molecule is utilized for each bilirubin molecule.

In summary, bilirubin conjugation can occur prematurely in utero in infants with prenatal hyperbilirubinemia. Serum unconjugated bilirubin concentrations greater than $2 \mathrm{mg} / \mathrm{dl}$ appear to be a prerequisite for formation of bilirubin conjugates in human neonates. Bilirubin conjugation in both premature and full-term infants displays a similar pattern of conjugation with monoconjugates appearing prior to the diconjugate. While other studies are needed to further elucidate the mechanisms responsible for bilirubin conjugation in the human newborn, it appears that bilirubin may play a fundamental role in initiation of bilirubin conjugation after birth.

Acknowledgment. The internal standard was generously provided by D. Lightner, University of Nevada, Reno, NV.

\section{REFERENCES}

1. Brown AK 1962 Neonatal jaundice. Pediat Clin North Am 9:575-603

2. Odell GB 1967 Physiologic hyperbilinubinemia in the neonatal period. N Engl J Med 277:193-195

3. Arias IM 1970 The pathogenesis of "physiologic" jaundice of the newborn: a re-evaluation. In: Bergsma D (ed) Bilirubin Metabolism in the Newborn. Birth Defects 6:55-59

4. Brown AK, Zuelzer WW 1958 Studies on the neonatal development of the glucuronide conjugating system. J Clin Invest 37:332-340

5. Dutton GJ 1959 Glucuronide synthesis in fetal liver and other tissues. Biochem J 71:141-148

6. Gartner LM, Lane D 1971 Hepatic metabolism and transport of bilirubin during physiologic jaundice in the newborn Rhesus monkey. Pediatr Res 5:413(abstr)

7. Strebel L, Cdell GB 1969 UDP glucuronyl transferase in rat liver: genetic variation and maturation. Pediatr Res 3:351-352

8. Thaler MM 1970 Substrate-induced conjugation of bilirubin in genetically deficient newborn rats. Science 170:555-556

9. Blanckaert N, Kabra PM, Farina FA, Stafford BE, Marton LJ, Schmid R 1980 Measurement of bilirubin and its monoconjugates and diconjugates in human serum by alkaline methanolysis and high performance liquid chromatography. J Lab Clin Med 96:198-212

10. Rosenthal P, Blanckaert N, Kabra PM, Thaler MM 1981 Liquid-chromatographic determination of bilirubin and its conjugates in rat serum and human amniotic fluid. Clin Chem 27:1704-1707

11. Grunewald JO, Cullen R, Bredfeldt J, Strope ER 1975 An efficient route to xanthobilirubic acid, an oxydipyrryl methene. Org Prep Proced Int 7:103110 
12. Odell GB 1970 In discussion of paper by Lester R, Jackson BT, Smallwood RA. In: Bergsma D (ed) Bilirubin Metabolism in the Newborn. Birth Defects 6:16-21

13. Bakken AF 1969 Effects of unconjugated bilirubin on bilirubin-UDP glucuronyl transferase activity in liver of newborn rats. Pediatr Res 3:205-209

14. Balistreri WF, Heubi JE, Suchy FJ 1983 Immaturity of the enterohepatic circulation in early life: factors predisposing to "physiologic" maldigestion and cholestasis. J Pediatr Gastroenterol Nutr 2:346-354

15. Balistreri WF, Suchy FJ, Farrell MK, Heubi JE 1981 Pathologic versus physiologic cholestasis: elevated serum concentrations of a secondary bile acid occurs only in the presence of hepatobiliary disease. J Pediatr 98:399-401

16. Suchy FJ, Balistreri WF, Heubi JE, Searcy JE, Levin RS 1981 Physiologic cholestasis: elevation of the primary serum bile acid concentrations in normal infants. Gastroenterology 80:1037-1041

\section{Announcement}

\section{Pediatric Critical Care Medicine Examination}

The Subspecialty Committee of Pediatric Critical Care Medicine of the American Board of Pediatrics will administer its first certifying examination on Friday, July 10, 1987.

The following criteria must be met to be eligible to sit for the examination:

1. Certification by the American Board of Pediatrics.

2. Two years of full-time subspecialty residency training in pediatric critical care medicine. OR Certification in pediatric cardiology, neonatal-perinatal medicine, or pediatric pulmonology based on completion of the full-time subspecialty residency training requirements in a program providing experience in pediatric critical care relevant to the subspecialty in which the applicant already holds certification plus one year of subspecialty residency training in pediatric critical care medicine. OR Five years in the practice of pediatric critical care medicine. A minimum of $50 \%$ of full-time professional activities must be spent in the practice of pediatric critical care medicine to receive credit. All practice time must be accrued before December 31, 1991. OR A combination of subspecialty residency training in pediatric critical care medicine and practice of pediatric critical care medicine to equal five years: a) For residencies of less than 12 months: one month of subspecialty residency equals one month of pediatric critical care medicine practice. b) For residencies of 12 to 23 months: one month of subspecialty residency equals two months of pediatric critical care medicine practice.

3. Verification of training and/or practice.

Each application will be considered individually and must be acceptable to the Subspecialty Committee of Pediatric Critical Care Medicine. The Subspecialty Committee recognizes that situations may arise that are not explained by the preceding information. In such cases, the individual may present his/her situation to the Credentials Committee by completing an application during the examination registration period.

Registration for this examination will extend from September 1, 1986, to December 31, 1986. Requests for applications received prior to the opening of registration will be held on file until that date, at which time application materials will be sent to those who have requested them.

The application fee for the examination is $\$ 800$ ( $\$ 275$ processing and evaluating fee plus $\$ 525$ examination fee). Candidates not approved to take the examination will be refunded the $\$ 525$ examination fee. The processing and evaluating fee will be retained.

Please direct inquiries to the American Board of Pediatrics, 111 Silver Cedar Court, Chapel Hill, NC 27514-1651. Telephone (919) 929-0461. 